\title{
Síndrome del cascanueces como causa de hematuria
}

\author{
S. Esquena Fernández, J.M. Abascal Junquera, E. Trilla Herrera, R. Martos Calvo, \\ C. Ramírez Sevilla, J. Morote Robles
}

Servicio de Urología. Hospital Vall d'Hebron. Barcelona.

Actas Urol Esp 2005; 29 (8): 805

$\mathrm{E}_{\mathrm{la}}^{\mathrm{l}}$ sindrome del cascanueces es provocado por la compresión de la vena renal izquierda entre la aorta abdominal y la arteria mesentérica superior, conduciendo a una hipertensión venosa renal. Este fenómeno provoca la aparición de varices en el hilio renal y a nivel periureteral. Su rotura dentro de la vía, dará lugar a la clásica hematuria. Esta entidad es una infrecuente causa de hematuria benigna lateralizada, y se ha sugerido que la etiología sería una anormal ramificación de la arteria mesentérica superior desde la aorta. Suele presentarse como hematuria monosintomática, siendo normal la exploración física. Son útiles para el diagnóstico, la TC, la arteriografía y la ureteroscopia. El tratamiento conservador se propone en casos de hematuria leve, mientras que la cirugía estaría indicada para casos de hematuria masiva y dolor, siendo el autotransplante de riñón izquierdo una opción terapéutica. En la imagen de nuestro caso se observa la gran dilatación de la vena renal izquierda provocada por la compresión de la

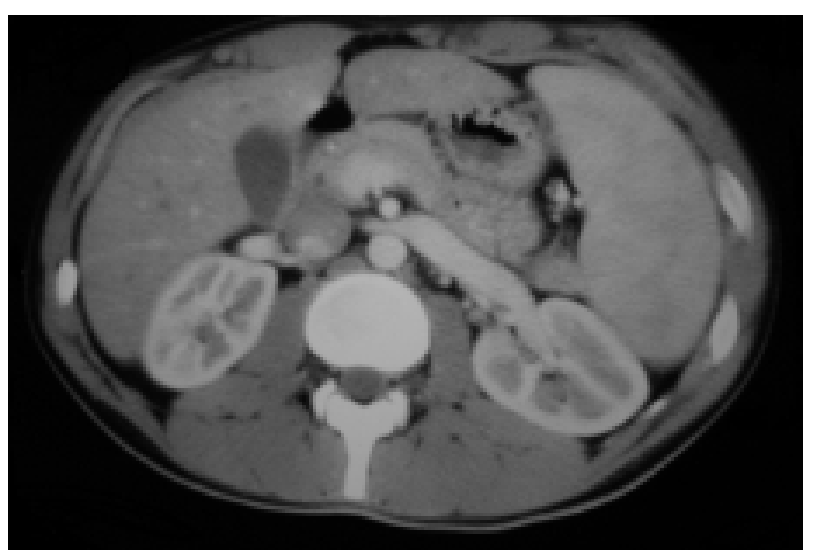

FIGURA 1

pinza aorto-mesentérica. Este paciente presentaba hematuria leve por lo que sigue controles periódicos.

Dr. S. Esquena Fernández Hospital Vall d’Hebron. Servicio de Urología. Passeig Vall d’Hebrón, 119-129

08035 Barcelona

doc99@eresmas.com 